\title{
Treadmill exercise ameliorates disturbance of spatial learning ability in scopolamine-induced amnesia rats
}

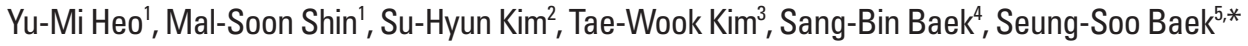 \\ 'Department of Physiology, College of Medicine, Kyung Hee University, Seoul, Korea \\ ${ }^{2}$ Department of Physical Education, Graduate School, Dankook University, Seoul, Korea \\ ${ }^{3}$ Department of Physical Education, College of Physical Education, Hanyang University, Seoul, Korea \\ ${ }^{4}$ Department of Psychiatry, Gangneung Asan Hospital, University of Ulsan College of Medicine, Gangneung, Korea \\ ${ }^{5}$ Department of Sport \& Health Science, College of Natural Science, Sangmyung University, Seoul, Korea
}

Alzheimer's disease is the most common neurodegenerative disease and this disease induces progressive loss of memory function Scopolamine is a non-selective muscarinic cholinergic receptor antagonist and it induces impairment of learning ability. Exercise is known to ameliorate memory deficits induced by various brain diseases. In the present study, we investigated the effect of treadmill exercise on spatial learning ability in relation with cell proliferation in the hippocampus using the scopolamine-induced amnesia mice. For the induction of amnesia, $1 \mathrm{mg} / \mathrm{kg}$ scopolamine hydrobromide was administered intraperitoneally once a day for 14 days. Morris water maze test for spatial learning ability was conducted. Immonofluorescence for 5-bromo-2-deoxyuridine (BrdU) and western blot for brain-derived neurotrophic factor (BDNF) and its receptor tyrosine kinase $B$ (TrkB) were performed. In the present results, scopolamine-induced amnesia mice showed deterioration of spatial learning ability. Inhibition of cell proliferation and suppression of BDNF and TrkB expressions were observed in the scopolamine-induced amnesia mice. Treadmill exercise improved spatial learning ability and increased cell proliferation through activating of BDNF-TrkB pathway in the amnesia mice. These findings offer a possibility that treadmill exercise may provide preventive or therapeutic value for the memory loss induced by variable neurodegenerative diseases including Alzheimer's disease.

Keywords: Scopolamine, Amnesia, Treadmill exercise, Cell proliferation, Spatial learning ability, Brain-derived neurotrophic factor

\section{INTRODUCTION}

Alzheimer's disease (AD) is most common neurodegenerative disease and this disease induces progressive loss of learning ability and memory function (Moosavi et al., 2012). The degree of memory loss is correlated with the severity of AD (Howes et al., 2003). Scopolamine is a non-selective muscarinic cholinergic receptor antagonist and it deteriorates learning ability and short-term memory. Scopolamine is used to create the amnesia animal model (Araujo et al., 2005; Heo et al., 2014). Scopolamine also inhibits central cholinergic neuronal activity (Konar et al., 2011). Central cholinergic system is closely associated with and neurogenesis and/or cell proliferation in the hippocampus (Kotani et al., 2006; Yoo et al., 2011).
Hippocampus plays a crucial brain area for the process of learning and memory (Kim et al., 2010). It is vulnerable to neuronal injury produced by scopolamine, resulting in the deficits of synaptic plasticity and spatial memory (Mattson et al., 2002). The generation of neurons in the hippocampus plays an important role in the learning ability and memory function. Neurogenesis in the hippocampal dentate gyrus is known to be enhanced by enriched environment, neurotrophic growth factors, and exercise, while adrenal steroids, opioid peptides, and stress inhibit it (Baek et al., 2012; Gould and Tanapat, 1999; Kim et al., 2003; van Praag et al., 1999).

Adult hippocampal neurogenesisis and neuroplasticity are modulated by many neurotrophic factors such as brain-derived neuro-
${ }^{*}$ Corresponding author: Seung-Soo Baek

Department of Sport \& Health Science, College of Natural Science, Sangmyung

University, 20 Hongjimun 2-gil, Jongno-gu, Seoul 110-743, Korea

Tel: +82-2-2287-5133, Fax: +82-2-2287-0075, E-mail: ssoop@smu.ac.kr

Received: June 18, 2014 / Accepted: June 19, 2014
This is an Open Access article distributed under the terms of the Creative Commons Attribution Non-Commercial License (http://creativecommons.org/licenses/by-nc/3.0/) which permits unrestricted non-commercial use, distribution, and reproduction in any medium, provided the original work is properly cited. 
trophic factor (BDNF), nerve growth factor (NGF), and neurotrophin-3 (Malberget al., 2000), Of these, BDNF has been intensively studied and shown to be involved in the learning and memory (Poo et al., 2001). BDNF is a neurotrophin involved in neuronal survival and plasticity that binds to high-affinity receptors, tyrosine kinase B (TrkB) (Givalois et al., 2004). BDNF-TrkB interaction promotes the survival and differentiation of neurons and synaptic plasticity of the central nervous systems (Kim et al., 2010; Lu et al., 2008).

The enhancing effects of exercise on learning ability and memory functions have been reported in many studies (Baek et al., 2012; Ji et al., 2014; Kim et al., 2010; van Praag et al., 1999). In the present study, we investigated the effect of treadmill exercise on spatial learning ability in relation with cell proliferation in the hippocampal dentate gyrus using the scopolamine-induced amnesia mice. For this study, Morris water maze test, immonofluorescence for 5-bromo-2'-deoxyuridine (BrdU) and western blot for brain-derived BDNF and TrkB were conducted.

\section{MATERIALS AND METHODS}

\section{Experimental animals}

Male ICR mice weighing $35 \pm 0.5 \mathrm{~g}$ were used in this experiment. The experimental procedures were performed in accordance with the animal care guidelines of the National Institutes of Health (NIH) and the Korean Academy of Medical Sciences. The mice were housed under controlled temperature $\left(20 \pm 2^{\circ} \mathrm{C}\right)$ and lighting (07:00 to 19:00 h) conditions with food and water available ad libitum. The mice were randomly divided into 4 groups ( $\mathrm{n}=10$ in each group): control group, exercise group, scopolamine-induced amnesia group, and scopolamine-induced amnesia and exercise group. All mice received $50 \mathrm{mg} / \mathrm{kg}$ BrdU (Sigma Chemical Co., St. Louis, MO, USA) intraperitoneally once a day $30 \mathrm{~min}$ before the treadmill exercises for 5 consecutive days, starting experiment.

\section{Administration of scopolamine}

To induce amnesia, $1 \mathrm{mg} / \mathrm{kg}$ scopolamine hydrobromide (Sigma Chemical Co.) dissolved in physiological saline was injected intraperitoneally once a day for 14 consecutive days, as the previously described method (Heo et al., 2014). The mice in the control group received saline instead of scopolamine. Morris water-maze test was carried out at $30 \mathrm{~min}$ after last injection of scopolamine.

\section{Treadmill exercise protocol}

The mice in the exercise groups were forced to run on a motorized treadmill for 30 min once a day for 14 days. Exercise load for the running groups consisted of running at a speed of 5 meters/ min with the $0^{\circ}$ inclination. The mice in the non-exercise groups were left on the treadmill without running for the same duration as the exercise groups.

\section{Morris water-maze test}

In order to evaluate the spatial learning ability in mice, occupancy time in the Morris water maze test was determined, as the previously described method (Kim et al., 2010; Sim et al., 2014). The water maze was a circular pool (diameter $=115 \mathrm{~cm}$, height $=22$ $\mathrm{cm})$ constructed of fiberglass. The water was maintained at a temperature of $22 \pm 2^{\circ} \mathrm{C}$. During testing in the water maze, a platform (diameter $=9 \mathrm{~cm}$, height $=20 \mathrm{~cm}$ ) was located $2 \mathrm{~cm}$ below the water surface in one of four locations in the pool. Clearly visible cues outside the basin were provided for orientation. The test consisted of three acquisition phases and two probe trials. In the acquisition phase, the mice had daily four trials for 3 consecutive days to find the platform submerged $2 \mathrm{~cm}$ under the water surface. For each trial, the mice were placed in the water, facing the wall of the tank, in one of the four start locations. The mice were allowed to search for the platform for $60 \mathrm{sec}$. If the mice found the platform, remaining on the platform for $10 \mathrm{sec}$ was permitted. If the mice did not find the platform within $60 \mathrm{sec}$, the mice were guided and allowed to remain on the platform for $10 \mathrm{sec}$. The interval between trials was $20 \mathrm{sec}$. After each training session, the mice were dried with a towel and returned to their cages. To assess spatial learning ability, the animals were subjected to the $60 \mathrm{sec}$ probe trial following the last training session, and then the platform was removed from the pool. The occupancy time in the quadrant platform was recorded automatically by a video tracking system (SMART; Pan-Lab, Barcelona, Spain).

\section{Tissue preparation}

The mice were sacrificed immediately after determining occupancy time. The mice were anesthetized using Zoletil $50^{\circledR}(10$ $\mathrm{mg} / \mathrm{kg}$, i.p.; Vibac Laboratories, Carros, France), transcardially perfused with $50 \mathrm{mM}$ phosphate-buffered saline (PBS), and fixed with a freshly prepared solution consisting of $4 \%$ paraformaldehyde in $100 \mathrm{mM}$ phosphate buffer (PB, pH 7.4). The brains were dissected and post-fixed in the same fixative method overnight, and transferred to a $30 \%$ sucrose solution for cryoprotection. Then, $40 \mu \mathrm{m}$ thick coronal sections were made using a freezing 
microtome (Leica, Nussloch, Germany). On average 10 slice sections in the hippocampal region were collected from each mice.

\section{BrdU immunofluorescence}

Immunofluorescence for the BrdU-positive and NeuN-positive cells in the hippocampal dentate gyrus was performed, according to the previously described method (Shin et al., 2013). The sections were first permeabilized by incubation in $0.5 \%$ Triton $\mathrm{X}-100$ in PBS for $20 \mathrm{~min}$, then pretreated in 50\% formamide-2 $\mathrm{X}$ standard saline citrate (SSC) at $65^{\circ} \mathrm{C}$ for $2 \mathrm{~h}$, denatured in $2 \mathrm{~N}$ $\mathrm{HCl}$ at $37^{\circ} \mathrm{C}$ for $30 \mathrm{~min}$, and rinsed twice in $100 \mathrm{mM}$ sodium borate $\left(\mathrm{pH}\right.$ 8.5). After washing in $\mathrm{PBS}$ for $15 \mathrm{~min}$ at $27^{\circ} \mathrm{C}$, the sections were followed by wash for $10 \mathrm{~min}$ three times at room temperature. The sections were incubated overnight with rat anti-BrdU antibody (1:200; Abcam, Cambridge, Cambridgeshire, UK) and mouse anti-NeuN antibody (1:400; Chemicon, Temecula, CA, USA). The sections were next incubated for $2 \mathrm{~h}$ with cy3-conjugated anti-rat secondary antibody (1:200; Jackson ImmunoResearch Laboratories, West Grove, PA, USA) for the BrdU antibody and fluorescein isothiocyanate (FITC)-conjugated anti-mouse secondary antibody (1:200; Jackson Immuno Research Laboratories) for the NeuN antibody. The sections were then mounted on gelatin-coated glass slides, and the cover slips were mounted using fluorescent mounting medium (Dako Cytomation, Carpinteria, CA, USA). The slides of the fluorescent images were captured using a confocal laser scanning microscopy (LSM700; Carl Zeiss, München-Hallbergmoos, Germany).

\section{Western blot analysis}

Western blot analysis was conducted for the determination of BDNF and TrkB expressions, as the previously described method (Kim et al., 2010). Hippocampal tissues were collected and then immediately frozen at $-70^{\circ} \mathrm{C}$. Hippocampal tissues were homogenized on ice, and lysed in a lysis buffer containing $50 \mathrm{mM}$ HEPES (pH 7.5), $150 \mathrm{mM} \mathrm{NaCl}, 10 \%$ glycerol, $1 \%$ Triton X-100, 1 mM PMSF, 1 mM EGTA, $1.5 \mathrm{mM} \mathrm{MgCl} 2 \cdot 6 \mathrm{H}_{2} \mathrm{O}, 1 \mathrm{mM}$ sodium orthovanadate, and $100 \mathrm{mM}$ sodiumfluoride. Protein content was measured using a Bio-Rad colorimetric protein assay kit (Hercules, CA, USA). Protein $(30 \mu \mathrm{g})$ was separated on SDS-polyacrylamide gels and transferred onto a nitrocellulose membrane. Mouse beta-actin antibody (1:500; Santa Cruz Biotechnology, Santa Cruz, CA, USA), rabbit BDNF antibody, and rabbit TrkB antibody (1:1,000; Santa Cruz Biotechnology) were used as the primary antibodies. Horseradish peroxidase-conjugated anti-rabbit antibody (1:3,000; Vector Laboratories, Burlingame, CA, USA) for BDNF and TrkB were used as the secondary antibodies. Experiments were performed under normal laboratory conditions and at room temperature, except for the transfer to membranes. The transfer was performed at $4{ }^{\circ} \mathrm{C}$ with a cold pack and prechilled buffer. Band detection was performed using enhanced chemiluminescence (ECL) detection kits (Santa Cruz Biotechnology).

\section{Data analysis}

The numbers of BrdU-positive cells in the hippocampal dentate gyrus were counted hemilaterally under a light microscope (Olympus, Tokyo, Japan), and they were expressed as the numbers of cells per $\mathrm{mm}^{2}$ in the hippocampal dentate gyrus. To compare the relative expressions of BDNF and TrkB, the detected bands were calculated densitometrically using Image-Pro Plus software (Media Cybernetics, Silver Spring, MD, USA). The data are expressed as the number of cells per $\mathrm{mm}^{2}$ of the hippocampus. Statistical analysis was performed using one-way ANOVA followed by Duncan's post-hoc test. The results are presented as the mean \pm standard error of the mean (SEM). Significance was set as $P<0.05$.

\section{RESULTS}

Effect of treadmill exercise on the time spent in the probe quadrant of Morris water maze test

Spatial learning ability was measured using the Morris-water maze test (Fig. 1). The time spent in the probe quadrant was $28.69 \pm 0.63 \%$ in the control group, $32.66 \pm 2.49 \%$ in control and exercise group, $22.27 \pm 0.72 \%$ in the scopolamine-induced amnesia group, and $28.00 \pm 1.39 \%$ in the scopolamine-induced amnesia and exercise group. The present results revealed that spatial learning ability in the mice was deteriorated by the induction of amnesia $(P<0.05)$. In contrast, treadmill exercise improved spatial learning ability in the scopolamine-induced amnesia mice $(P<0.05)$. In the normal mice, treadmill exercise enhanced spatial learning ability.

\section{Effect of treadmill exercise on the number of BrdU- positive in the dentate gyrus of hippocampus}

Cell proliferation in the hippocampal dentate gyrus is presented in Fig. 2. The number of BrdU-positive cells in the hippocampal dentate gyrus was $167.70 \pm 3.44 / \mathrm{mm}^{2}$ in the control group, $244.22 \pm 8.00 / \mathrm{mm}^{2}$ in control and exercise group, $93.33 \pm 5.11 /$ $\mathrm{mm}^{2}$ in the scopolamine-induced amnesia group, and 134.24 $11.46 / \mathrm{mm}^{2}$ in the scopolamine-induced amnesia and exercise 

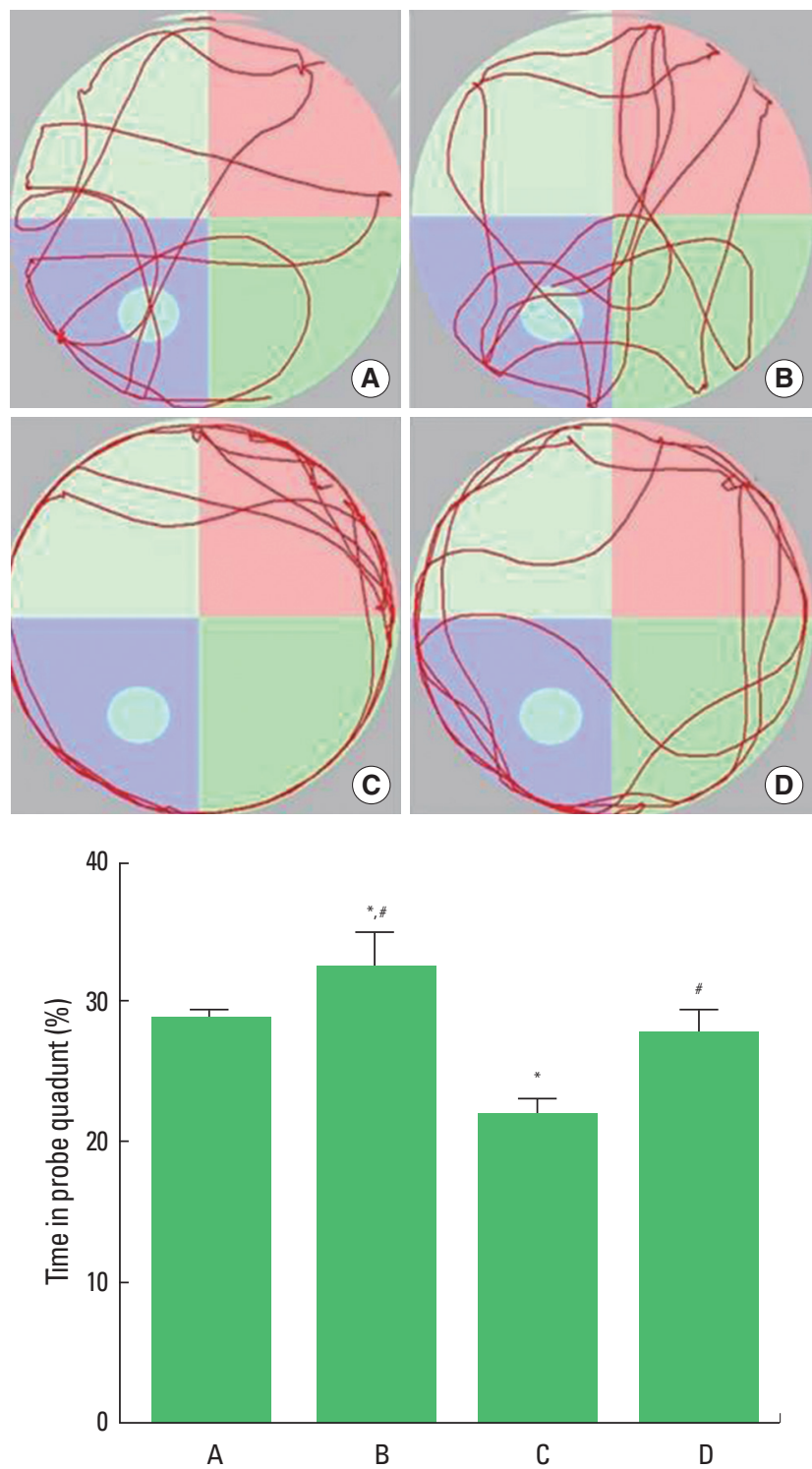

Fig. 1. Effect of treadmill exercise on spatial learning ability. (A) Control group, (B) Exercise group, (C) Scopolamine-induced amnesia group, and (D) Scopolamine-induced amnesia and exercise group. The data are presented as the mean \pm standard error of the mean (SEM). ${ }^{*} P<0.05$ compared to the control group. ${ }^{\sharp} P<0.05$ compared to the scopolamine-induced amnesia group.

group. The present results showed that cell proliferation in the hippocampal dentate gyrus was significantly suppressed in the scopolamine-induced amnesia mice $(P<0.05)$. In contrast, treadmill exercise enhanced cell proliferation in the scopolamine-induced amnesia mice $(P<0.05)$. In the normal rats, treadmill exercise increased cell proliferation in the hippocampal dentate gyrus $(P<0.05)$
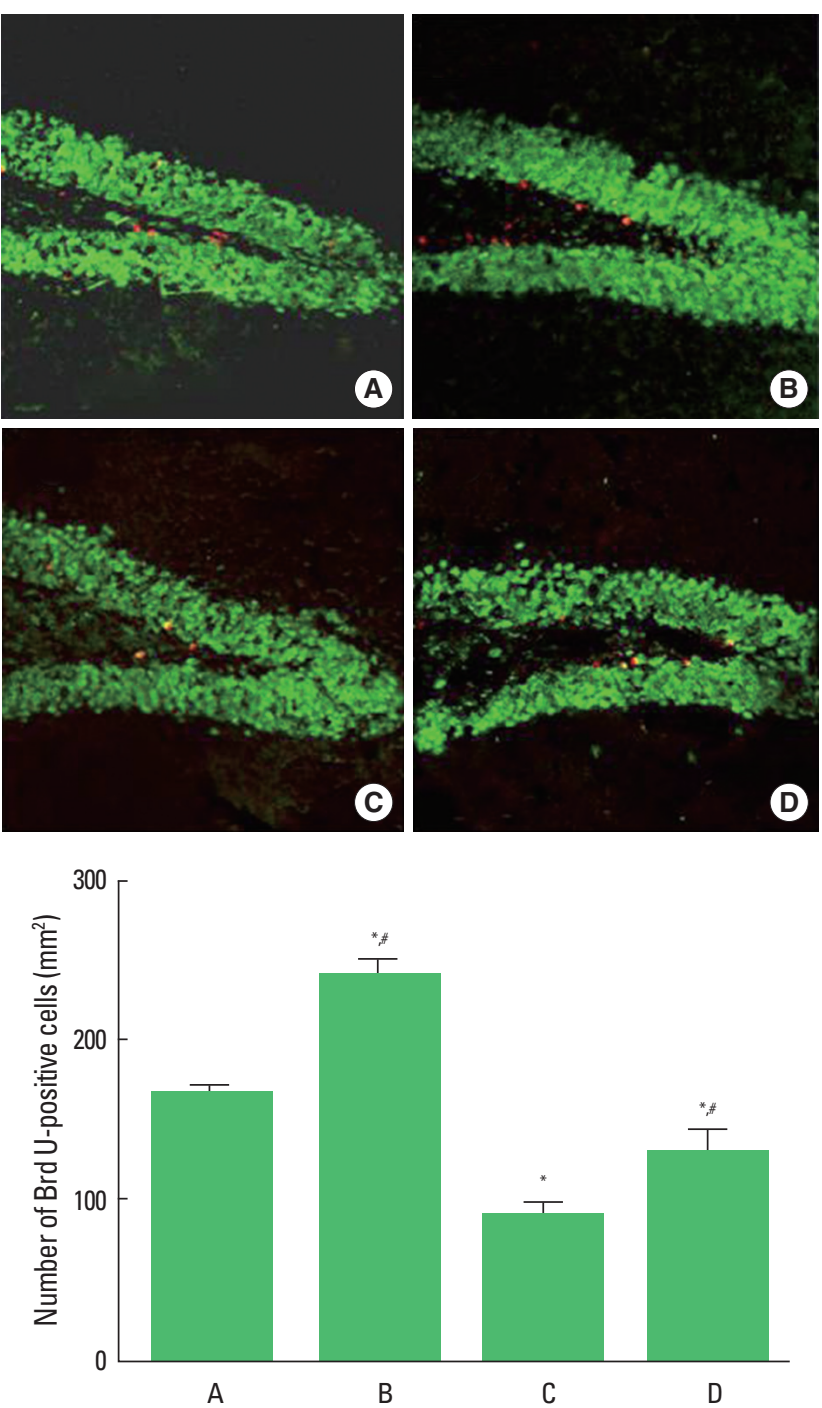

Fig. 2. Effect of treadmill exercise on cell proliferation in the hippocampal dentate gyrus. (A) Control group, (B) Exercise group, (C) Scopolamine-induced amnesia group, and (D) Scopolamine-induced amnesia and exercise group. The scale bar represents $100 \mu \mathrm{m}$. The data are presented as the mean \pm standard error of the mean (SEM). ${ }^{*} P<0.05$ compared to the control group. ${ }^{*} P<0.05$ compared to the scopolamine-induced amnesia group.

\section{Effect of treadmill exercise on BDNF and TrkB expressions in the hippocampus}

We determined the relative expression of BDNF in the hippocampus (Fig. 3). When the level of BDNF ( $14 \mathrm{kDa}$ ) in the control group was set at 1.00, the level of BDNF was $1.65 \pm 0.52$ in the control and exercise group, $0.35 \pm 0.22$ in the scopolamine-induced amnesia group, and $0.88 \pm 0.27$ in the scopolamine-induced amnesia and exercise group. The present results demonstrated that the expression of BDNF in the hippocampus was decreased in the scopolamine-induced amnesia mice $(P<0.05)$. In 

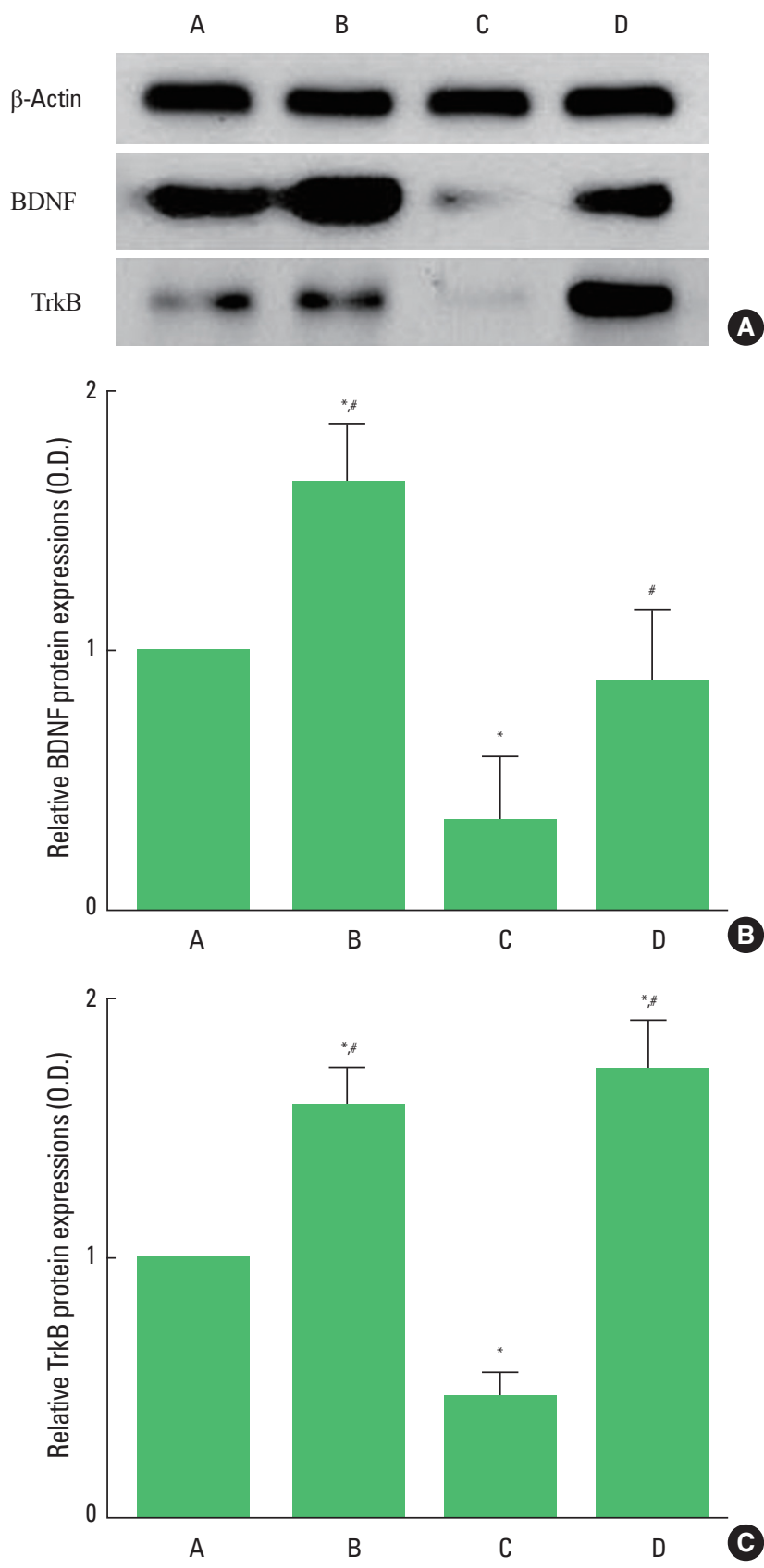

Fig. 3. Effect of treadmill exercise on brain-derived neurotrophic factor (BDNF) and tyrosine kinase $B$ (TrkB) expressions in the hippocampus. (A) Control group, (B) Exercise group, (C) Scopolamine-induced amnesia group, and (D) Scopolamine-induced amnesia and exercise group. The data are presented as the mean \pm standard error of the mean (SEM). ${ }^{*} P<0.05$ compared to the control group. ${ }^{\sharp} P<0.05$ compared to the scopolamine-induced amnesia group.

contrast, treadmill exercise remarkably increased the BDNF expression in the scopolamine-induced amnesia mice $(P<0.05)$. In the normal mice, treadmill exercise increased the BDNF expression in the hippocampus $(P<0.05)$.
We determined the relative expression of $\operatorname{TrkB}$ in the hippocampus (Fig. 3). When the level of TrkB (95-145 kDa) in the control group was set at 1.00, the level of TrkB was $1.59 \pm 0.14$ in the control and exercise group, $0.47 \pm 0.29$ in the scopolamine-induced amnesia group, and $1.73 \pm 0.56$ in the scopolamine-induced amnesia and exercise group. The present results showed that the expression of $\operatorname{TrkB}$ in the hippocampus was decreased in the scopolamine-induced amnesia mice $(P<0.05)$. In contrast, treadmill exercise remarkably increased the TrkB expression in the scopolamine-induced amnesia mice $(P<0.05)$. In the normal mice, treadmill exercise increased the $\operatorname{TrkB}$ expression in the hippocampus $(P<0.05)$.

\section{DISCUSSION}

$\mathrm{AD}$ is the most common cause of progressive loss of memory in the elderly (Rubio et al., 2007). Scopolamine dysregulates cholinergic activity, resulting in the deficits of the learning ability and memory tasks (Elvander et al., 2004). Scopolamine-induced memory impairment is closely associated with the cholinergic dysfunction (Sharma et al., 2010). Short-term memory was deteriorated in the scopolamine-induced amnesia mice (Heo et al., 2014). In the present results, spatial learning ability was deteriorated in the scopolamine-induced amnesia mice, while treadmill exercise ameliorated spatial learning deficits in the amnesia mice.

Lesion in the cholinergic nuclei leads to the suppression of neurogenesis in the hippocampus (Cooper-Kuhn et al., 2004). Scopolamine also inhibits neurogenesis in the hippocampus (Kotani et al., 2006). Enhanced hippocampal neurogenesis by physical exercise is closely associated with improving memory function (van Praag et al., 2005; Kim et al., 2010). In the present results, cell proliferation in the hippocampal dentate gyrus was decreased in the scopolamine-induced amnesia mice, while treadmill exercise increased neurogenesis in the amnesia mice.

Increased neurogenesis and improved memory function by exercise are induced by BDNF up-regulation in the brain (Cotman and Berchtold, 2002). Exercise increases the level of BDNF in the hippocampus and stimulates hippocampal neurogenesis (Rhodes et al., 2003). BDNF has been suggested as the potential mediator for the exercise-derived hippocampal plasticity and neurogenesis (Cotman and Berchtold, 2002; Kim et al., 2010). Decrement in BDNF and TrkB contributed memory deficits in the AD (Li et al., 2010).

Heo et al. (2014) demonstrated that treadmill exercise ameliorated short-term memory impairment through suppressing ace- 
tylcholine esterase and enhancing angiogenesis in the scopolamine-induced amnesia mice. In the present results, BDNF and TrkB expressions in the hippocampus were suppressed in the scopolamine-induced amnesia mice, while treadmill exercise enhanced BDNF and TrkB expressions in the amnesia mice.

In the present study, induction of scopolamine-induced amnesia showed inhibition of cell proliferation and suppression of BDNF and TrkB expressions in the hippocampus, and resulted in the impairment of spatial learning ability. Treadmill exercise improved spatial learning ability by increasing cell proliferation through activation of BDNF-TrkB pathway. The present results offer a possibility that treadmill exercise may provide preventive or therapeutic value for the memory loss induced by variable neurodegenerative diseases including $\mathrm{AD}$.

\section{CONFLICT OF INTEREST}

No potential conflict of interest relevant to this article was reported.

\section{ACKNOWLEDGMENTS}

This work was supported by the National Research Foundation of Korea Grant funded by the Korean Government (NRF-2011327-G00124).

\section{REFERENCES}

Araujo JA, Studzinski CM, Milgram NW. Further evidence for the cholinergic hypothesis of aging and dementia from the canine model of aging. Prog Neuropsychopharmacol Biol Psychiatry 2005;29:411-422.

Baek SS, Jun TW, Kim KJ, Shin MS, Kang SY, Kim CJ. Effects of postnatal treadmill exercise on apoptotic neuronal cell death and cell proliferation of maternal separated rat pups. Brain Dev 2012;34:45-56.

Cooper-Kuhn CM, Winkler J, Kuhn HG. Decreased neurogenesis after cholinergic forebrain lesion in the adult rat. J Neurosci Res 2004; 77:155-165.

Cotman CW, Berchtold NC. Exercise: a behavioral intervention to enhance brain health and plasticity. Trends Neurosci 2002;25:295-301.

Elvander E, Schött PA, Sandin J, Bjelke B, Kehr J, Yoshitake T, Ogren SO. Intraseptal muscarinic ligandsand galanin: Influence on hippocampal acetylcholine and cognition. Neuroscience 2004;126:541-557.

Givalois L, Arancibia S, Alonso G, Tapia-Arancibia L. Expression of brain-derived neurotrophic factor in the rat median eminence cells with sensitivity to stress. Endocrinology 2004;145:4737-4747.
Gould E, Tanapat P. Stress and hippocampal neurogenesis. Biol Psychiatry 1999;46:1472-1479.

Heo YM, Shin MS, Lee JM, Kim CJ, Baek SB, Kim KH, Baek SS. Treadmill exercise ameliorates short-term memory disturbance in scopolamine-induced amnesia rats. Int Neurourol J 2014;18:16-22.

Howes MJ, Perry NS, Houghton PJ. Plants with traditional uses and activities, relevant to the management of Alzheimer's disease and other cognitive disorders. Phytother Res 2003;17:1-18.

Ji ES, Kim CJ, Park JH, Bahn GH. Duration-dependence of the effect of treadmill exercise on hyperactivity in attention deficit hyperactivity disorder rats. J Exerc Rehabil 2014;10:75-80.

Kim SE, Ko IG, Kim BK, Shin MS, Cho S, Kim CJ, Kim SH, Baek SS, Lee $E K$, Jee YS. Treadmill exercise prevents aging-induced failure of memory through an increase in neurogenesis and suppression of apoptosis in rat hippocampus. Exp Gerontol 2010;45:357-365.

Kim YP, Kim HB, Jang MH, Lim BV, Kim YJ, Kim H. Magnitude- and time-dependence of the effect of treadmill exercise on cell proliferation in the dentate gyrus of rats. Int J Sports Med 2003;24:114-117.

Konar A, Shah N, Singh R, Saxena N, Kaul SC, Wadhwa R, Thakur MK. Protective role of Ashwagandha leaf extract and its component withanone on scopolamine-induced changes in the brain and brain-derived cells. PLoS One 2011;6:27265.

Kotani S, Yamauchi T, Teramoto T, Ogura H. Pharmacological evidence of cholinergic involvement in adult hippocampal neurogenesis in rats. Neuroscience 2006;142:505-514.

Li F, Gong QH, Wu Q, Lu YF, Shi JS. Icariin isolated from Epimediumbrevicornum Maxim attenuates learning and memory deficits induced by D-galactose in rats. Pharmacol Biochem Behav 2010;96:301305.

Lu Y, Christian K, Lu B. BDNF: a key regulator for protein synthesis-dependent LTP and long-term memory? Neurobiol Learn Mem 2008; 89:312-323

Malberg JE, Eisch AJ, Nestler EJ, Duman RS. Chronic antidepressant treatment increases neurogenesis in adult rat hippocampus. J Neurosci 2000;20:9104-9110.

Mattson MP, Chan SL, Duan W. Modification of brain aging and neurodegenerative disorders by genes, diet, and behavior. Physiol Rev 2002;82:637-672.

Moosavi M, Khales GY, Abbasi L, Zarifkar A, Rastegar K. Agmatine protects against scopolamine-induced water maze performance impairment and hippocampal ERK and Akt inactivation. Neuropharmacology 2012;62:2018-2023.

Poo MM. Neurotrophins as synaptic modulators. Nat Rev Neurosci 2001;2:24-32.

Rhodes JS, van Praag H, Jeffrey S, Girard I, Mitchell GS, Garland T Jr, 
Gage FH. Exercise increases hippocampal neurogenesis to high levels but does not improve spatial learning in mice bred for increased voluntary wheel running. Behav Neurosci 2003;117:1006-1016.

Rubio J, Dang H, Gong M, Liu X, Chen SL, Gonzales GF. Aqueous and hydroalcoholic extracts of black maca (Lepidiummeyenii) improve scopolamine-induced memory impairment in mice. Food Chem Toxicol 2007;45:1882-1890.

Sharma D, Puri M, Tiwary AK, Singh N, Jaggi AS. Antiamnesic effect of stevioside in scopolamine-treated rats. Indian J Pharmacol 2010; 42:164-167.

Shin MS, Ko IG, Kim SE, Kim BK, Kim TS, Lee SH, Hwang DS, Kim CJ, Park JK, Lim BV. Treadmill exercise ameliorates symptoms of methimazole-induced hypothyroidism through enhancing neurogenesis and suppressing apoptosis in the hippocampus of rat pups. Int J Dev Neurosci 2013;31:214-223.
Sim YJ. Treadmill exercise alleviates impairment of spatial learning ability through enhancing cell proliferation in the streptozotocin-induced Alzheimer's disease rats. J Exerc Rehabil 2014;10:81-88.

van Praag H, Kempermann G, Gage FH. Running increases cell proliferation and neurogenesis in the adult mouse dentate gyrus. Nat Neurosci 1999;2:266-270

van Praag H, Shubert T, Zhao C, Gage FH. Exercise enhances learning and hippocampal neurogenesis in aged mice. J Neurosci 2005;25:86808685.

Yoo DY, Kim W, Yoo KY, Lee CH, Choi JH, Kang IJ, Yoon YS, Kim DW, Won MH, Hwang IK. Effects of Nelumbonucifera rhizome extract on cell proliferation and neuroblast differentiation in the hippocampal dentate gyrus in a scopolamine-induced amnesia animal model. Phytother Res 2011;25:809-815. 